\title{
Association Studies in Yield and Grain Quality Traits in Aromatic and Non Aromatic Families of Rice
}

\author{
A. R. Priyanka ${ }^{1 *}$, P. Jeyaprakash ${ }^{1}$, K. Baghyalakshmi ${ }^{2}$ and Ramchander $^{2}$ \\ ${ }^{1}$ Department of Plant Breeding and Genetics, \\ Agricultural College and Research Institute, Madurai-625 104, Tamil Nadu, India \\ ${ }^{1}$ Department of Rice, Centre for Plant Breeding and Genetics, \\ TNAU, Coimbatore - 641 003, Tamil Nadu, India \\ ${ }^{2}$ ICAR-Central Institute for Cotton Research (RS), Coimbatore, India \\ ${ }^{2}$ ICRISAT, Patencheru, Hyderabad, India \\ *Corresponding author
}

A B S T R A C T

K e y w o r d s
Correlation, Yield,
Grain quality, Rice,
Elongation ratio
Article Info
Accepted:
23 April 2020
Available Online:
10 May 2020

The exploitation of yield potential through inter sub specific (inter-racial) hybridization become a challenging task for rice breeders. Grain yield improvement is considered to be prime objective of any breeding programme, quality traits are yet another important consideration of rice breeding in India. Association of yield and yield components and among grain quality traits thus assumes a unique prominence as the basis for selecting desirable high yielding genotypes with good grain quality characters. Correlation analysis is basic and foremost effort to find out strategies for plant selection. Hundred grain weight showed significant and negative correlation with grain yield per plant. Linear elongation ratio showed significant and positive correlation with kernel breadth, kernel breadth before cooking, kernel length after cooking, and LB ratio after cooking and hence selection of these traits will serve in improvement of LER. Direct effect of number of productive tillers per plant was found to be high on single plant yield.

\section{Introduction}

Rice is one of the pivotal stable food and primary food source for most of the world population. Breed a variety with high yield and good grain quality characters is an important goal of breeders. The international rice market is highly segmented because consumer preference is highly heterogeneous, not only across countries but also within countries. The rice grain quality traits generally include milling quality, appearance quality, and nutritional quality in terms of cooking and eating quality which are most important for the consumers. Hence selection for improved milling, cooking, eating and processing qualities is crucial to meet consumers' preference and industry standards. 
Rice grain quality is important not only from the consumer's point of view, but also for rice farmers. Development of plant breeding strategy mainly depends on the nature of association of major quantitative traits with yield, quality or any other economic trait. Correlation coefficient ensures the degree of association, genetic or non-genetic relationship between two or more characters which forms the basis for selection. The degree of correlation between the traits is a key factor especially in complex and economic trait such as yield. Path analysis simply splits the correlation coefficient into the measures of direct and indirect effect of a set of independent variables on the dependent variables.

\section{Materials and Methods}

The experimental material comprised of 437 $\mathrm{F}_{3}$ families of $\mathrm{CB} 08504 \mathrm{X}$ Improved Pusa Basmati 1. All the 437 families were raised. All the agronomical practices were done. Based on grain type 50 single plants were selected. Yield contributing traits viz., days to 50 per cent flowering (days), plant height $(\mathrm{cm})$, number of tillers per plant, number of productive tillers per plant, panicle length (cm), hundred grain weight, grain yield per plant and fifteen grain quality characters viz., hulling percentage, milling percentage, head rice recovery, kernel length, kernel breadth, length / breadth ratio, kernel length before cooking, kernel breadth before cooking, kernel length after cooking, kernel breadth after cooking, LB ratio after cooking, linear elongation ratio, breadth wise expansion ratio, gelatinization temperature, gel consistency and amylose content were recorded for 50 single plants.

\section{Hulling percentage}

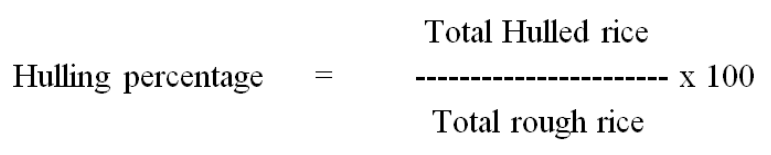

\section{Milling percentage}

$$
\text { Milling percentage }=\frac{\text { Total Milled rice }}{\text { Total rough rice }}
$$

\section{Head rice recovery (HRR)}

Head rice recovery or milling recovery is the estimate of head rice (milled rice with more than two third size) and expressed in percentage

$$
\text { Head rice recovery }(\%)=\begin{gathered}
\text { Total head rice } \\
\text { - } \\
\text { Total rough rice }
\end{gathered}
$$

\section{Kernel length}

Length of ten unbroken brown rice was measured using graph sheet and the mean was expressed in millimeter $(\mathrm{mm})$

\section{Kernel breadth}

Breadth of ten unbroken rice was measured using a graph sheet and the mean was expressed in $\mathrm{mm}$.

\section{Linear elongation ratio (LER)}

The ratio of mean length of cooked rice to mean length of milled rice was computed as linear elongation ratio (Juliano and Perez, 1984).

Gelatinization temperature (GT) was estimated based on alkali spreading score (ASV) of milled rice. The method developed by Little et al., (1958) was used to score alkali spreading value. Gel consistency (GC)was analyzed based on the method described by Cagampang et al., (1973).Statistical analysis were done using TNAUSTAT. Correlation figure was done using Graph Pad Prism software. 
In path analysis, grain yield per plant and linear elongation ratio was considered as dependent characters for yield characters and grain quality characters respectively.

\section{Results and Discussion}

Grain yield per plant showed significant and negative correlation with hundred grain weight. Plant height showed significant positive correlation with number of tillers per plant, days to fifty percent flowering showed significant positive correlation with plant height, plant height showed significant positive correlation with number of productive tillers per plant, number of tillers per plant showed significant positive correlation with number of productive tillers per plant. In grain quality characters, linear elongation ratio showed significant and positive correlation with kernel breadth, kernel breadth before cooking, kernel length after cooking, LB ratio after cooking and significant negative association with head rice recovery, kernel length, LB ratio, kernel length before cooking and breadth wise expansion ratio. Krishnaveni and Rani (2006), Mahalingam (2008) reported that kernel breadth, kernel length after cooking showed positive association with linear elongation ratio. Asish et al., (2007) reported that kernel length showed negative association with linear elongation ratio. Chauhan et al., (1995), Arulmozhi and Muthuswamy (2013) reported that LB ratio showed negative association with LER. Hence selection of these traits viz., kernel breadth, kernel breadth before cooking, kernel length after cooking, LB ratio after cooking will serve in improvement of LER (Fig. 1 and 2; Table 1-4).

Inter correlation among the quality character

Kernel length showed positive association with LB ratio, kernel length before cooking, kernel length after cooking, breadth wise expansion ratio and negative association with kernel breadth, kernel breadth before cooking. Santhipriya et al., (2017) and Venkanna et al., (2014) reported that kernel length positive association with LB ratio. Kernel breadth exhibited positive association with kernel breadth before cooking and significant and negative association with LB ratio, kernel length before cooking and breadth wise expansion ratio. LB ratio exhibited significant positive association with kernel length before cooking, breadth wise expansion ratio and significant negative association with kernel breadth before cooking. Kernel length before cooking showed significant positive association with kernel length after cooking, breadth wise expansion ratio and significant negative association with kernel breadth before cooking.

Kernel breadth before cooking showed significant negative association with breadth wise expansion ratio. Kernel length after cooking showed significant positive association with LB ratio after cooking. Kernel breadth after cooking showed significant positive association with breadth wise expansion ratio and significant association with LB ratio after cooking.

\section{Path analysis for yield attributing characters}

Days to $50 \%$ flowering, plant height and number of productive tillers per plant exhibited positive direct effect on grain yield per plant. Direct effect of number of productive tillers per plant was found to be high. AshutoshSawarkar and Senapati (2014) reported that days to fifty per cent flowering showed low positive direct effects on grain yield per plant and Nandan et al., (2010), Ashim and Ghosh (2012) reported that plant height showed low direct effects on grain yield/plant. Selection based on number of 
productive tillers per plant is very effective.

Table.1 Correlation analysis for morphological traits

\begin{tabular}{|l|l|l|l|l|l|l|l|}
\hline Character & DFF & PH & NT/P & NPT/P & PL & HGW & GY/P \\
\hline DFF & 1 & $0.301^{*}$ & 0.184 & 0.189 & 0.056 & -0.210 & 0.279 \\
\hline PH & & 1 & $0.391^{* *}$ & $0.434^{* *}$ & 0.200 & -0.116 & 0.266 \\
\hline NT/P & & & 1 & $0.979^{* *}$ & 0.070 & 0.049 & 0.013 \\
\hline NPT/P & & & & 1 & 0.092 & 0.041 & 0.072 \\
\hline PL & & & & & 1 & -0.094 & 0.075 \\
\hline HGW & & & & & & 1 & $-0.343^{*}$ \\
\hline GY/P & & & & & & & 1 \\
\hline
\end{tabular}

Table.2 Path coefficient analysis of morphological traits

\begin{tabular}{|c|c|c|c|c|c|c|c|}
\hline Character & DFF & PH & NT/P & NP/P & PL & HGW & GY/P \\
\hline DFF & 0.1775 & 0.0450 & -0.2150 & 0.2137 & -0.0007 & 0.0583 & 0.2788 \\
\hline $\mathbf{P H}$ & 0.0533 & 0.1498 & -0.4578 & 0.4908 & -0.0026 & 0.0322 & 0.2658 \\
\hline NT/P & 0.0326 & 0.0586 & -1.1698 & 1.1062 & -0.0009 & -0.0137 & 0.0131 \\
\hline NPT/P & 0.0335 & 0.0650 & -1.1448 & 1.1304 & -0.0012 & -0.0114 & 0.0717 \\
\hline PL & 0.0100 & 0.0300 & -0.0822 & 0.1043 & -0.013 & 0.0261 & 0.0753 \\
\hline HGW & -0.0372 & -0.0173 & -0.0576 & 0.0464 & 0.0012 & -02782 & -0.3428 \\
\hline
\end{tabular}

Residual effect: 0.8664

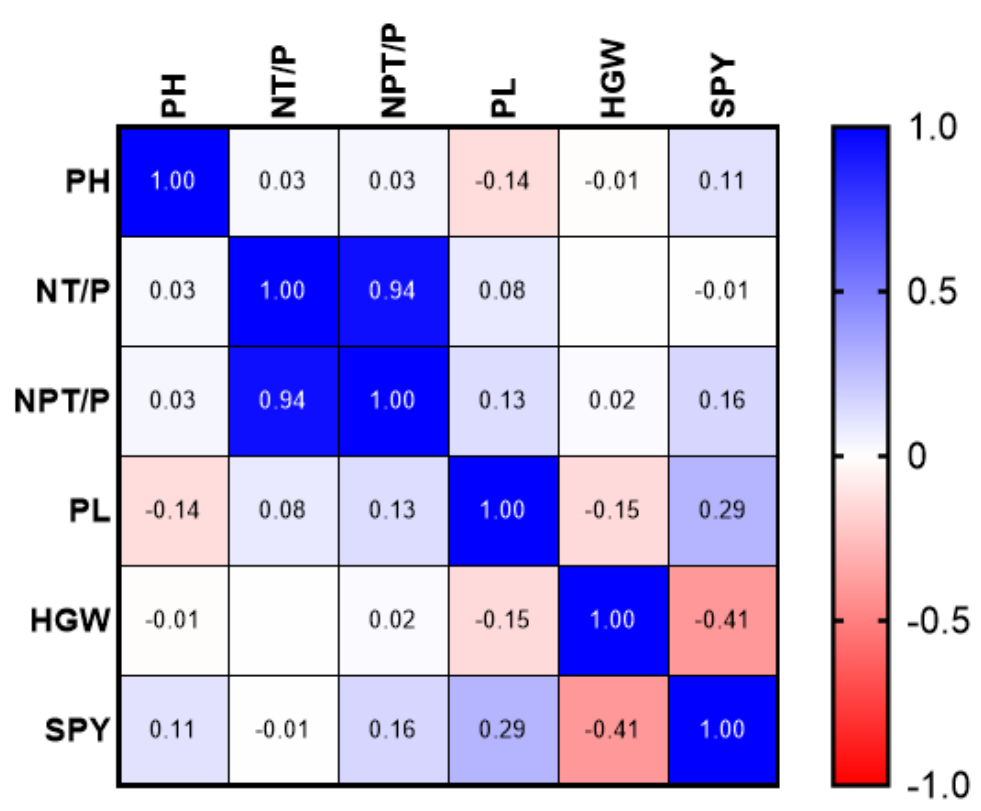

Fig.1 Correlation coefficient among yield and yield contributing traits 
Table.3 Correlation analysis for grain quality traits

\begin{tabular}{|c|c|c|c|c|c|c|c|c|c|c|c|c|c|c|c|c|}
\hline Traits & Н \% & М\% & HRR & KL & KB & LBR & KLBC & KBBC & KLAC & KBAC & LBAC & BER & GC & GT & AC & LER \\
\hline H \% & 1 & -0.020 & 0.234 & -0.168 & 0.054 & -0.129 & -0.146 & 0.085 & -0.275 & -0.042 & -0.0249 & -0.098 & 0.177 & -0.078 & -0.115 & -0.093 \\
\hline М\% & & 1 & 0.018 & 0.014 & -0.060 & 0.031 & 0.087 & 0.020 & -0.039 & -0.079 & -0.002 & -0.056 & -0.059 & 0.001 & -0.0276 & -0.147 \\
\hline HRR & & & 1 & 0.253 & -0.075 & 0.191 & 0.162 & -0.107 & -0.176 & -0.160 & -0.061 & -0.011 & 0.013 & -0.098 & -0.021 & $-0.297^{*}$ \\
\hline KL & & & & 1 & $-0.378^{* *}$ & $0.847^{* *}$ & $0.913^{* * *}$ & $-0.485^{* *}$ & $0.330^{* * *}$ & 0.220 & 0.178 & $0.549^{* *}$ & 0.046 & -0.149 & -0.214 & $-0.487^{* *}$ \\
\hline KB & & & & & 1 & $-0.808^{* *}$ & $-0.420^{* *}$ & $0.928^{* *}$ & -0.021 & 0.227 & -0.152 & $-0.696^{* * *}$ & -0.091 & -0.109 & 0.158 & $0.345^{* *}$ \\
\hline LBR & & & & & & 1 & $0.813^{* *}$ & $-0.838^{* *}$ & 0.205 & 0.018 & 0.178 & $0.754^{* *}$ & 0.087 & -0.040 & -0.221 & $-0.512^{* * *}$ \\
\hline KLBC & & & & & & & 1 & $-0.499^{* *}$ & $0.448^{* * *}$ & 0.254 & 0.274 & $0.584^{* *}$ & 0.156 & -0.140 & -0.203 & $-0.464^{* *}$ \\
\hline KBBC & & & & & & & & 1 & -0.011 & 0.163 & -0.108 & $-0.806^{* *}$ & -0.176 & 0.021 & 0.144 & $0.421^{* *}$ \\
\hline KLAC & & & & & & & & & 1 & 0.244 & $0.810^{* *}$ & 0.135 & -0.035 & -0.037 & 0.055 & $0.520^{* *}$ \\
\hline KBAC & & & & & & & & & & 1 & $-0.360^{* * *}$ & $0.448^{* *}$ & 0.110 & -0.068 & 0.060 & 0.115 \\
\hline LBAC & & & & & & & & & & & 1 & -0.138 & -0.115 & 0.027 & 0.063 & $0.418^{* *}$ \\
\hline BER & & & & & & & & & & & & 1 & 0.230 & -0.068 & -0.093 & $-0.306^{*}$ \\
\hline GC & & & & & & & & & & & & & 1 & -0.078 & -0.028 & -0.109 \\
\hline GT & & & & & & & & & & & & & & 1 & -0.014 & 0.035 \\
\hline $\mathrm{AC}$ & & & & & & & & & & & & & & & 1 & 0.189 \\
\hline LER & & & & & & & & & & & & & & & & 1 \\
\hline
\end{tabular}


Table.4 Path coefficient analysis of grain quality traits

\begin{tabular}{|c|c|c|c|c|c|c|c|c|c|c|c|c|c|c|c|c|}
\hline Traits & Н \% & М\% & HRR & KL & KB & LBR & KLBC & КВBC & KLAC & KBAC & $\mathbf{L B}(\mathrm{AC})$ & BER & GC & GT & $\mathrm{AC}$ & LER \\
\hline H \% & -0.131 & -0.013 & 0.0001 & -0.324 & 0.259 & 0.1285 & 0.275 & -0.102 & 0.563 & -3.682 & 0.726 & 1.206 & 1.822 & 1.841 & -2.971 & -0.403 \\
\hline М\% & 0.0225 & 0.080 & 0.0002 & 0.2034 & -0.176 & -0.095 & -0.157 & 0.074 & -0.243 & 1.938 & -0.555 & -0.630 & -1.037 & -1.017 & 1.766 & 0.1724 \\
\hline HRR & 0.0133 & 0.020 & 0.001 & 0.0643 & -0.059 & -0.030 & -0.104 & 0.0079 & -0.299 & 1.3586 & -0.084 & -0.322 & -0.453 & -0.511 & 0.4407 & 0.0402 \\
\hline KL & 0.094 & 0.036 & 0.0001 & 0.453 & -0.340 & -0.183 & -0.357 & 0.1362 & -0.692 & 4.625 & -0.978 & -1.436 & -2.236 & -2.278 & 3.568 & 0.4103 \\
\hline KB & 0.093 & 0.038 & 0.0002 & 0.4212 & -0.366 & -0.177 & -0.366 & 0.133 & -0.718 & 4.801 & -0.966 & -1.489 & -2.180 & -2.398 & 3.528 & 0.352 \\
\hline LBR & 0.082 & 0.037 & 0.0001 & 0.407 & -0.319 & -0.204 & -0.373 & 0.123 & -0.738 & 4.689 & -0.871 & -1.333 & -2.03 & -2.194 & 3.073 & 0.349 \\
\hline KLBC & 0.078 & 0.027 & 0.0002 & 0.3508 & -0.290 & -0.164 & -0.461 & 0.096 & -0.995 & 5.839 & -0.644 & -1.496 & -2.011 & -2.245 & 2.259 & 0.339 \\
\hline KBBC & 0.081 & 0.036 & 0 & 0.372 & -0.294 & -0.151 & -0.268 & 0.165 & -0.277 & 3.365 & -1.172 & -1.309 & -2.080 & -1.944 & 3.752 & 0.275 \\
\hline KLAC & 0.0679 & 0.018 & 0.0003 & 0.287 & -0.241 & -0.138 & -0.421 & 0.0421 & -1.092 & 5.4008 & -0.274 & -1.226 & -1.553 & -1.944 & 1.394 & 0.3196 \\
\hline KBAC & 0.0807 & 0.026 & 0.0002 & 0.3492 & -0.293 & -0.159 & -0.448 & 0.092 & -0.981 & 6.010 & -0.629 & -1.565 & -2.019 & -2.332 & 2.265 & 0.395 \\
\hline $\mathbf{L B}(\mathrm{AC})$ & 0.079 & 0.037 & 0.0001 & 0.370 & -0.295 & -0.148 & -0.248 & 0.162 & -0.250 & 3.158 & -1.197 & -1.305 & -2.040 & -1.958 & 3.863 & 0.227 \\
\hline BER & 0.082 & 0.026 & 0.0002 & 0.339 & -0.284 & -0.141 & -0.359 & 0.113 & -0.697 & 4.899 & $-0 . .813$ & -1.920 & -2.001 & -2.899 & 3.950 & 0.293 \\
\hline GC & 0.096 & 0.033 & 0.0002 & 0.41 & -0.323 & -0.167 & -0.375 & 0.139 & -0.685 & 4.903 & -0.987 & -1.552 & -2.475 & -2.096 & 3.80 & 0.401 \\
\hline GT & 0.078 & 0.026 & 0.0002 & 0.336 & -0.285 & -0.145 & -0.337 & 0.1048 & -0.690 & 4.554 & -0.762 & -1.809 & -1.686 & -3.077 & 3.937 & 0.244 \\
\hline $\mathrm{AC}$ & 0.083 & 0.030 & 0.0001 & 0.3447 & -0.275 & -0.133 & -0.222 & 0.1325 & -0.324 & 2.899 & -0.985 & -1.615 & -1.834 & -2.58 & 4.697 & 0.2174 \\
\hline
\end{tabular}

Residual effect:0.766 


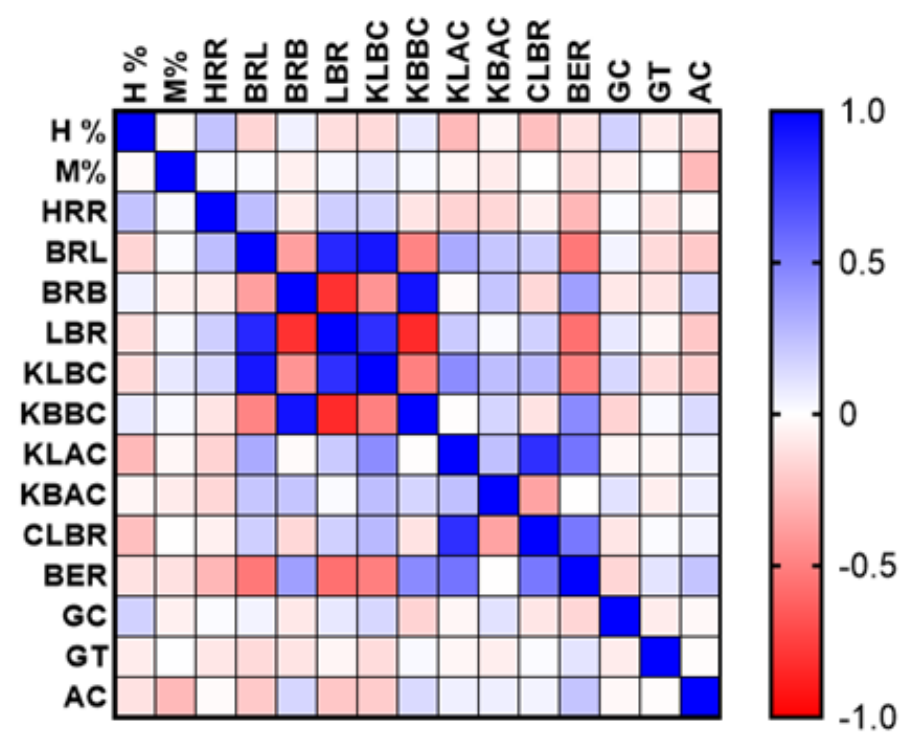

Fig.2 Correlation coefficient among grain quality traits

Sandhya et al., (2014) reported similar results. The indirect effect of plant height exhibited high positive on number of productive tillers per plant and negative through number of tillers per plant. Number of tillers per plant exhibited very high positive indirect effect on number of panicle per plant. Very high negative indirect effect was recorded by number of productive tillers per plant through number of tillers per plant.

\section{Path analysis for quality character}

Out of sixteen character subjected to assess the direct effects of linear elongation ratio, six characters viz., milling percentage, head rice recovery, kernel length, kernel breadth before cooking, kernel breadth after cooking, amylose content showed positive direct effect on linear elongation ratio. Premkumar et al., (2016) reported the same results. The direct effect of kernel breadth after cooking and amylose content were found to be very high on LER. Hulling percentage exhibited very high positive indirect effect on breadth wise elongation ratio, gel consistency and gelatinization temperature. Very high positive indirect effect was exhibited by milling percentage on kernel breadth after cooking and amylose content. The indirect effect of head rice recovery was found to be very high on kernel breadth after cooking. Very high positive indirect effect was observed in kernel length on kernel breadth after cooking and amylose content. The indirect effect of kernel breadth was found to be on kernel breadth after cooking, amylose content. Kernel breadth after cooking and amylose content was found to be very high indirect effect on LB ratio. The indirect effect of gel consistency was found to be very high on kernel breadth after cooking and amylose content. Very high indirect effect of gelatinization temperature was observed on kernel breadth after cooking and amylose content

\section{References}

Arulmozhi, R. and A. Muthuswamy. 2013. Correlation studies on grain yield and its component traits in rice (Oryza sativa L). Int. J. Sci. Res. 2(11): 2277 81709.

Ashim.C and P.D. Ghosh. 2012. Grain dimension studies in view of kernel 
weight development in traditional rice of West Bengal. Int. J. Biosci.10(2): 95102.

Ashutosh, S and B. K. Senapati. 2014.Polygenic variations and cause effect relationship in some photoinsensitive recombinant inbred lines (RIL's) of Basmati derivative. Afr. J. Biotechnol. 13(1): 112 - 118.

Asish, K., Binodh, R. Kalaiyarasi and K. Thiyagarajan. 2007. Genetic parameter studies on quality traits in rice. Madras Agric. J. 94 (1-6): 109-113.

Cagampang, G.B., C.M. Perez and B.O.Juliano. 1973. A gel consistency test for eating quality rice. J. Sci. Food Agric. 243: 1589- 1594.

Chauhan, J. S., V. S. Chauhan and S. B. Lodh. 1995. Comparative analysis of variability and correlations between quality components in traditional rainfed upland and low land rice. Indian J Genet., 55 : 6-12.

Julino, B.O and C. M. Perez. 1984. Results of collaborative test on the measurement of grain elongation of milled rice during cooking .J. Cereal Sci. 2: 281-292.

Krishnaveni, B and N. S. Rani. 2006. Association of grain yield with quality characteristics and other yield components in rice. Oryza. 43(4): 320322.

Little, R. R., G.B. Hilder and E. H. Dawson. 1958. Differential effect of dilute alkali on 25 varieties of milled white rice. Cereal Chemistry, 35 (2): 111-126.

Mahalingam, A. 2008.Genetic Analysis of Yield, Grain quality and Blast Resistance in Rice (Oryza sativa L.) through North Carolina. M.Sc (Ag.)Thesis, TNAU, Coimbatore. India.

Nandan, R., Sweta and S.K. Singh. 2010. Character association and path analysis in Rice (Oryza sativaL.) genotypes. World Journal of Agricultural Sciences.6 (2): 201-206.

Premkumar R., R. P. Gnanamalar and C. R. Anandakumar. 2016. Correlation and path coefficient analysis of grain quality traits in rice (Oryza sativa L.). Indian J. Agric. Res., 50 (1): 27-32

Sandhya, G., S. Babu and Ravikumar. 2014. Genetic variability, interrelationship and path analysis for yield improvement of rice genotypes. The Bioscan. 9 (3): 1161-1164.

Santhipriyach., Y. Suneetha, D. Ratnababu and V. Srinivasarao. 2017. Interrelationship and path analysis for yield and quality characters in rice (Oryza sativa L.). International journal of science, Environment and Technology. 6(1): 381-390.

Venkanna, V., M. V. B. Rao, S. Raju, V.T. Raoand N. Lingaiah. 2014. Association analysis of $\mathrm{F}_{2}$ generation in Rice (Oryza sativa. L.).Int. J. Pure App. Biosci. 2 (2): 278-283.

\section{How to cite this article:}

Priyanka, A. R., P. Jeyaprakash, K. Baghyalakshmi and Ramchander. 2020. Association Studies in Yield and Grain Quality Traits in Aromatic and Non Aromatic Families of Rice. Int.J.Curr.Microbiol.App.Sci. 9(05): 2940-2947. doi: https://doi.org/10.20546/ijcmas.2020.905.337 